\title{
Cross-protection against European swine influenza viruses in the context of infection immunity against the 2009 pandemic H1N1 virus: studies in the pig model of influenza
}

\author{
Yu Qiu, Karl De hert and Kristien Van Reeth*
}

\begin{abstract}
Pigs are natural hosts for the same influenza virus subtypes as humans and are a valuable model for cross-protection studies with influenza. In this study, we have used the pig model to examine the extent of virological protection between a) the 2009 pandemic H1N1 (pH1N1) virus and three different European H1 swine influenza virus (SIV) lineages, and b) these $\mathrm{H} 1$ viruses and a European H3N2 SIV. Pigs were inoculated intranasally with representative strains of each virus lineage with 6- and 17-week intervals between $\mathrm{H} 1$ inoculations and between $\mathrm{H} 1$ and $\mathrm{H} 3$ inoculations, respectively. Virus titers in nasal swabs and/or tissues of the respiratory tract were determined after each inoculation. There was substantial though differing cross-protection between $\mathrm{pH} 1 \mathrm{~N} 1$ and other $\mathrm{H} 1$ viruses, which was directly correlated with the relatedness in the viral hemagglutinin (HA) and neuraminidase (NA) proteins. Cross-protection against $\mathrm{H} 3 \mathrm{~N} 2$ was almost complete in pigs with immunity against H1N2, but was weak in H1N1/pH1N1-immune pigs. In conclusion, infection with a live, wild type influenza virus may offer substantial cross-lineage protection against viruses of the same HA and/or NA subtype. True heterosubtypic protection, in contrast, appears to be minimal in natural influenza virus hosts. We discuss our findings in the light of the zoonotic and pandemic risks of SIVs.
\end{abstract}

\section{Introduction}

Swine influenza viruses (SIVs) are important for the swine industry and as zoonotic agents. Moreover, they can lead to the emergence of novel pandemic influenza viruses for humans. In Europe, four lineages of SIV are enzootic in swine populations. An H1N1 virus of wholly avian origin became established in European swine in 1979 [1]. In the mid 1980s, this H1N1 virus reassorted with descendants of the 1968 Hong Kong human pandemic H3N2 virus $[2,3]$. The resulting H3N2 SIV lineage has human-like hemagglutinin (HA) and neuraminidase (NA) genes and avian-like internal genes. The third lineage, H1N2, was first reported in 1994, and is a reassortant virus that retains most of the genome of the H3N2 SIV, but has acquired an $\mathrm{H} 1$ gene from human seasonal viruses from the 1980s [4,5]. The 2009 pandemic H1N1 (pH1N1) virus is a reassortant with the NA and matrix (M)

\footnotetext{
* Correspondence: kristien.vanreeth@ugent.be

Laboratory of Virology, Faculty of Veterinary Medicine, Ghent University, Salisburylaan 133, B-9820 Merelbeke, Belgium
}

genes derived from the European avian-like H1N1 SIV and the remaining genes from North American triplereassortant H1 SIVs [6]. The pH1N1 virus was first detected in humans in April 2009 and only later in swine, but it has become widespread in swine worldwide due to large-scale reverse zoonotic transmissions [7]. Thus, while all four SIV lineages have a distinct HA and/or $\mathrm{NA}$, the pH1N1 also has a different set of internal genes compared to the three previously established SIVs. A growing number of reassortants between these four lineages has been reported in recent years, especially between pH1N1 and previously established SIVs [8].

The increasing number of H1 SIV lineages in Europe and other continents, and the geographic differences in the prevailing lineages have spurred interests in the extent of cross-protection between them. Prior infection of pigs with a European avian-like H1N1 SIV largely protects against subsequent infection with the pH1N1 [9], or with a North American triple-reassortant H1N1 SIV [10], despite the absence of cross-reactive serum hemagglutination-inhibition 
(HI) antibodies against the challenge virus. It remains unknown to what extent prior infection with pH1N1 offers protection against the previously established European H1 SIVs. This question is also of public health concern as the global spread of pH1N1 may generate cross-reactive immunity against some H1 SIVs in the human population, making them less likely candidates for future pandemics.

Apart from cross-protection between variants of the same HA subtype, cross-protection between viruses of different HA subtypes (heterosubtypic protection) has also been described. Heterosubtypic protection has been repeatedly shown in rodents and ferrets [11-15], but only rarely in natural hosts of influenza. In an experimental pig infection study with European SIVs, only 1 out of 5 H1N1-immune pigs tested positive for the H3N2 challenge virus in oropharyngeal swabs, for 1 day only. However, challenge control pigs in that study also had minimal virus titers in oropharyngeal swabs, and nasal swabs or tissues of the respiratory tract were not examined [16]. Epidemiological data support the existence of heterosubtypic immunity in humans that were exposed simultaneously or consecutively to epidemic human seasonal H1N1 and H3N2 viruses $[17,18]$. Also, the 1957 pandemic H2N2 virus appeared to have a lower disease incidence in adults previously infected with an H1N1 virus [19]. Yet, the significance and importance of heterosubtypic immunity in natural influenza virus hosts remain unclear. In this study, we sought to study cross-protection between a) pH1N1 and various $\mathrm{H} 1 \mathrm{SIVs}$, and b) these distinct $\mathrm{H} 1$ SIVs and H3N2. We use the pig as a natural host for SIVs and a model for influenza in humans.

\section{Material and methods}

Viruses and their genetic and antigenic relationships

Viruses for pig inoculation were propagated in embryonated chicken eggs and used at the third or fourth passage. Their genetic constellations are shown in Figure 1.
A/California/04/09 is a representative $\mathrm{pH} 1 \mathrm{~N} 1$, while sw/ Gent/28/10 (H1N1), sw/Gent/26/12 (H1N2) and sw/ Gent/172/08 (H3N2) are representative for SIVs that are enzootic in Western Europe. Sw/Côtes d'Armor/0046/08 is an occasionally reported reassortant H1N1 (rH1N1) SIV with the $\mathrm{H} 1$ derived from the European H1N2 SIV lineage and the N1 from the European H1N1 lineage [20].

The sequences of the HA1 and NA segments of the 5 viruses were available in GenBank (accession numbers FN646093, FN646099, KC142127, KC142128 and KP406524-KP406529). The HA1 and NA segments were compared at the amino acid level using the MEGALIGN program (DNASTAR, Madison, WI, USA). Amino acid differences at putative antigenic sites of the $\mathrm{H} 1$ and $\mathrm{N} 2$ proteins, as defined previously [21,22], were identified by alignment using MEGA5 software [23]. Antigenic characterization of the 5 viruses was performed by HI, virus-neutralization (VN) and neuraminidase-inhibition (NI) assays, using pig sera collected at 2 weeks after inoculation with each individual virus.

\section{Experimental design}

Forty 6-week-old pigs from an influenza negative farm were randomly assigned to 8 groups $(n=5)$ as shown in Table 1. Each group was housed in a separate biosafety level-2 HEPA-filtered isolation unit. All experiments were authorized by the Ethical and Animal Welfare Committee of the Faculty of Veterinary Medicine, Ghent University. Virus inoculations of pigs were performed intranasally, using $7.0 \log _{10} 50 \%$ egg infectious doses $\left(\mathrm{EID}_{50}\right)$ of the respective viruses in $3 \mathrm{~mL}$ ( $1.5 \mathrm{~mL}$ per nostril). Pigs were unanesthetized and held in a vertical position with the neck stretched. The inoculum was instilled into the middle nasal cavity by insertion of a $15-\mathrm{mm}$ plastic cannula attached to a $5-\mathrm{mL}$ syringe.

The first experiment was designed to examine whether infection immunity against pH1N1 offers protection

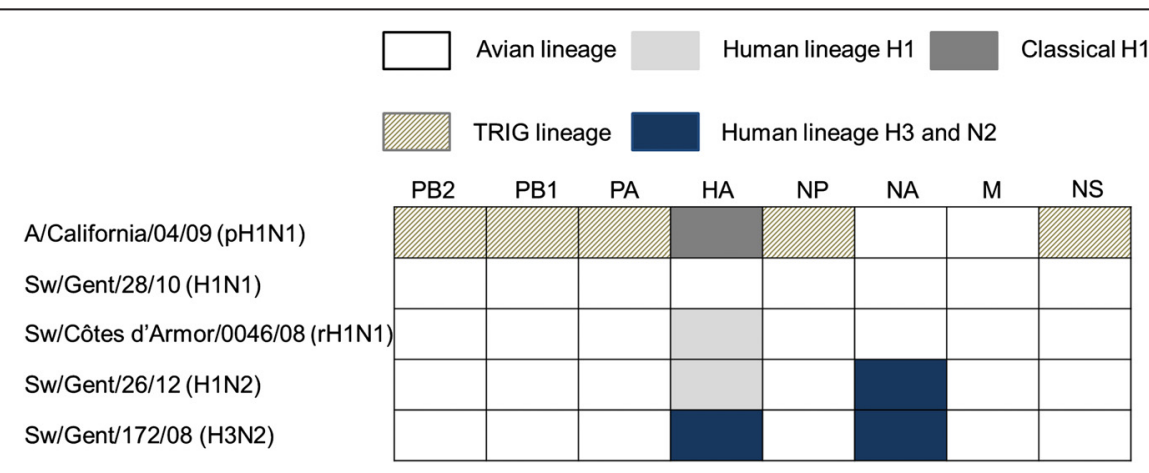

Figure 1 Genetic constellations of the five viruses used in this study. Abbreviations: PB2, polymerase basic 2; PB1, polymerase basic 1; PA, polymerase acidic; HA, hemagglutinin; NP, nucleoprotein; NA, neuraminidase; M, matrix; NS, nonstructural; TRIG, triple-reassortant internal genes, which are derived from swine (M, NS and NP), human (PB1) and avian (PB2 and PA) influenza viruses forming a constellation of genes that is well conserved in North American swine influenza viruses. 
Table 1 Experimental design

\begin{tabular}{|c|c|c|c|}
\hline \multirow[b]{3}{*}{ Group } & \multicolumn{3}{|c|}{ Viruses used for inoculation } \\
\hline & Experiment 1 & & Experiment 2 \\
\hline & 7 weeks $^{a}$ & 13 weeks $^{a}$ & 30 weeks $^{a}$ \\
\hline A & $\mathrm{pH} 1 \mathrm{~N} 1$ & $\mathrm{pH} 1 \mathrm{~N} 1$ & $\mathrm{H} 3 \mathrm{~N} 2$ \\
\hline B & $\mathrm{pH} 1 \mathrm{~N} 1$ & $\mathrm{H} 1 \mathrm{~N} 1$ & $\mathrm{H} 3 \mathrm{~N} 2$ \\
\hline C & $\mathrm{pH} 1 \mathrm{~N} 1$ & $\mathrm{rH} 1 \mathrm{~N} 1$ & - \\
\hline $\mathrm{D}$ & $\mathrm{pH} 1 \mathrm{~N} 1$ & $\mathrm{H} 1 \mathrm{~N} 2$ & $\mathrm{H} 3 \mathrm{~N} 2$ \\
\hline E & PBS & $\mathrm{H} 1 \mathrm{~N} 1$ & $\mathrm{H} 3 \mathrm{~N} 2$ \\
\hline $\mathrm{F}$ & PBS & $\mathrm{rH} 1 \mathrm{~N} 1$ & - \\
\hline G & PBS & $\mathrm{H} 1 \mathrm{~N} 2$ & $\mathrm{H} 3 \mathrm{~N} 2$ \\
\hline $\mathrm{H}$ & PBS & PBS & H3N2 \\
\hline
\end{tabular}

${ }^{\mathrm{a}}$ The age of pigs at the time of virus inoculation.

against infection with European H1 SIVs (Table 1). Four groups of pigs (A, B, C and D) were inoculated with $\mathrm{pH} 1 \mathrm{~N} 1$ virus, and the remaining four groups (E, F, G and $\mathrm{H}$ ) were mock-inoculated with phosphate-buffered saline (PBS). Six weeks later, the pH1N1-immune pigs were inoculated with the same $\mathrm{pH} 1 \mathrm{N1}$ virus (group A), or with 1 of 3 European H1 SIVs: H1N1 (group B), rH1N1 (group C), or H1N2 (group D). Three groups of influenza naïve pigs served as H1N1 (group E), rH1N1 (group F), or H1N2 (group G) challenge controls. Group H was inoculated again with PBS. To determine virus excretion, nasal swabs for virus titration were collected daily from all pigs from $0-8$ days post-primary inoculation and 0-7 days post-secondary inoculation. Blood samples for serology were collected at 0 and 14 days post-primary inoculation, and at $0,5,7,10$ and 14 days post-secondary inoculation.

The second experiment aimed at studying the heterosubtypic protection between $\mathrm{H} 1$ and $\mathrm{H} 3$ viruses (Table 1). Six groups from the first experiment (A, B, D, E, G and H) were inoculated with $\mathrm{H} 3 \mathrm{~N} 2,17$ weeks after the secondary inoculation. Nasal swabs for virus titration were collected daily from all pigs from $0-7$ days post-tertiary inoculation, or until euthanasia. Two pigs per group were euthanized at 4 days post-tertiary inoculation to examine virus titers of the entire respiratory tract: nasal mucosa respiratory and olfactory regions, tonsil, trachea, apical, cardiac, and diaphragmatic lobes of the left and right lungs, and the accessory lung lobe. Each tissue sample was collected and titrated separately. Blood samples for serology were collected at 0 and 14 days post-tertiary inoculation.

\section{Virus titration}

Sterile nasal swabs (Copan 160C, Copan Italia S.p.A.) were weighed before and after collection to determine virus titers per $100 \mathrm{mg}$ nasal secretions. Swabs from both nostrils were suspended in $1 \mathrm{~mL}$ sterile PBS supplemented with antibiotics. Tissues were weighed and homogenized in sterile PBS with antibiotics to obtain $20 \%(\mathrm{w} / \mathrm{v})$ homogenates. Nasal swab specimens and tissue homogenates were titrated in Madin-Darby canine kidney (MDCK) cells by the $50 \%$ tissue culture infectious doses $\left(\mathrm{TCID}_{50}\right)$ assay as described elsewhere [24].

\section{Serological assays}

Serum antibody responses were examined in $\mathrm{HI}, \mathrm{VN}$ and NI assays, as described elsewhere [25,26]. All sera collected before and at 2 weeks after each inoculation were examined against all 5 viruses in all 3 assays. At 5, 7, 10 and 14 days post-secondary inoculation, additional $\mathrm{VN}$ assays against the respective challenge $\mathrm{H} 1$ viruses were performed. Antibody titers were expressed as the reciprocal of the highest serum dilution that showed complete inhibition of HA of 4 hemagglutinating units of virus (HI assay), $50 \%$ neutralization of $100 \mathrm{TCID}_{50}$ of virus in MDCK cells (VN assay), or 50\% reduction of NA activity (NI assay). Starting dilutions were 1:2 in the VN assay, and 1:10 in HI and NI assays.

\section{Statistics}

Nasal virus shedding in each group was quantified by calculation of the area under the curve (AUC). Mann-Whitney tests were used to compare antibody levels between any two experimental groups, and before and after inoculation in each group. Differences were considered significant when $p<0.05$. GraphPad Prism5 software (GraphPad Software, San Diego, CA, USA) was used for all statistical analyses.

Table 2 Percent identity of the amino acid sequences of viral hemagglutinin (HA1) and neuraminidase (NA) segments

\begin{tabular}{|c|c|c|c|c|c|c|c|c|c|c|}
\hline \multirow[t]{2}{*}{ Virus } & \multicolumn{2}{|c|}{ A/California/04/09 } & \multicolumn{2}{|c|}{ Sw/Gent/28/10 } & \multicolumn{2}{|c|}{ Sw/Côtes d'Armor/0046/08 } & \multicolumn{2}{|c|}{ Sw/Gent/26/12 } & \multicolumn{2}{|c|}{ Sw/Gent/172/08 } \\
\hline & $\overline{\mathrm{HA} 1}$ & NA & $\overline{\mathrm{HA} 1}$ & NA & $\overline{\mathrm{HA} 1}$ & NA & $\overline{\mathrm{HA} 1}$ & NA & $\overline{\mathrm{HA} 1}$ & NA \\
\hline A/California/04/09 (pH1N1) & 100 & 100 & & & & & & & & \\
\hline Sw/Gent/28/10 (H1N1) & 73 & 91 & 100 & 100 & & & & & & \\
\hline Sw/Côtes d'Armor/0046/08 (rH1N1) & 72 & 91 & 70 & 97 & 100 & 100 & & & & \\
\hline Sw/Gent/26/12 (H1N2) & 71 & 41 & 69 & 40 & 90 & 40 & 100 & 100 & & \\
\hline Sw/Gent/172/08 (H3N2) & 34 & 42 & 35 & 40 & 32 & 39 & 33 & 84 & 100 & 100 \\
\hline
\end{tabular}




\section{Results}

Genetic and antigenic relationships between pH1N1 and European SIVs

Genetic relationships between viruses were assessed by comparison of the homology in viral HA1 and NA amino acid sequences (Table 2). Antigenic relationships between viruses were examined in cross-HI, VN and NI assays, using monospecific pig sera (Table 3). The rH1N1 and H1N2 viruses showed $90 \%$ amino acid sequence identity in their HA1 segments and cross-reactivity in $\mathrm{HI}$ and VN assays, reflecting the same human-like HA lineage of the two viruses. The HA1 segments of $\mathrm{H} 1 \mathrm{~N} 1, \mathrm{rH} 1 \mathrm{~N} 1$ and H1N2 had a similar homology (71-73\%) to the classical $\mathrm{H} 1$ of pH1N1. Alignment of HA1 antigenic sites of pH1N1 with those of $\mathrm{H} 1 \mathrm{~N} 1, \mathrm{rH} 1 \mathrm{~N} 1$ and $\mathrm{H} 1 \mathrm{~N} 2$ revealed 17, 26 and 27 amino acid differences, respectively (Additional file 1). Cross-reactivity between $\mathrm{pH} 1 \mathrm{~N} 1$ and other European H1 SIVs was absent in the HI assay, and rare in the $\mathrm{VN}$ assay. $\mathrm{H} 3 \mathrm{~N} 2$ failed to cross-react with any $\mathrm{H} 1$ viruses in $\mathrm{HI}$ and $\mathrm{VN}$ assays.

The H1N1 and rH1N1 showed 97\% amino acid identity in their NAs, which were closely related to the NA of pH1N1 (91\% identity), reflecting the same avian-like N1 lineage of the three viruses. Unfortunately, the complete antigenic sites on N1 neuraminidase have not been defined yet. The human-like NAs of H1N2 and H3N2 had $84 \%$ amino acid identity and 10 residue differences in antigenic sites (Additional file 2). Consistent with the genetic relatedness, cross-reactivity in the NI assay was observed between viruses of the same avian-like N1 or human-like N2 lineage.

\section{Experiment 1: protection against challenge with various European $\mathrm{H} 1$ SIVs in pigs with infection immunity against pH1N1}

After primary inoculation with $\mathrm{pH} 1 \mathrm{~N} 1$, pigs from groups $\mathrm{A}, \mathrm{B}, \mathrm{C}$ and D had similar mean AUC values (range from 24.9-27.4) and nasal shedding during 6-7 days. The mockinoculated pigs tested negative for virus at all time points.
Figure 2A shows mean virus titers in nasal swabs postsecondary inoculation with $\mathrm{pH} 1 \mathrm{~N} 1, \mathrm{H} 1 \mathrm{~N} 1, \mathrm{rH} 1 \mathrm{~N} 1$ or $H 1 N 2$. The respective challenge control groups (E, F and G) excreted high titers of the challenge viruses for 5-6 days (mean $\mathrm{AUC}=23.7,25.1$ and 23.6, respectively). In contrast, pH1N1-immune pigs showed complete protection (AUC = 0 ) against challenge with the homologous virus (group A) or with H1N1 (group B), and nearly complete protection against challenge with $\mathrm{rH1N} 1$ (group C) (mean AUC = 0.1). Virus excretion was detectable in 3 out of 5 pigs from group $\mathrm{C}$, for 1 day only and at minimal virus titers. A slightly weaker protection was observed after challenge with H1N2 (group D): 4 out of 5 pigs had virus shedding for $1-3$ days (mean AUC $=2.1$ ).

Prior to the start of the experiment, pigs were seronegative against all tested influenza viruses in $\mathrm{HI}, \mathrm{VN}$ and NI assays. At 2 weeks post-primary inoculation with $\mathrm{pH} 1 \mathrm{~N} 1$, pigs from groups $\mathrm{A}, \mathrm{B}, \mathrm{C}$ and $\mathrm{D}$ had similar antibody titers $(p>0.05)$ against the homologous virus in all assays. The geometric mean titers (GMTs) are shown in Table 3. At 6 weeks post-primary inoculation (time of the secondary inoculation with various $\mathrm{H} 1$ viruses), the $\mathrm{HI}$, VN and NI GMTs against pH1N1 were 39, 106 and 260, respectively. Cross-reactive antibodies against $\mathrm{H} 1 \mathrm{~N} 1$, rH1N1 and $\mathrm{H} 1 \mathrm{~N} 2$ were undetectable in all pH1N1immune pigs in the HI assay, but most pigs had low crossreactive VN titers. Higher cross-reactive NI titers were detected against H1N1 (GMT 36) than against rH1N1 (GMT 17) $(p<0.05)$. The challenge control pigs (groups E, F and $\mathrm{G}$ ) remained seronegative before the secondary inoculation, but had developed HI, VN and NI antibodies against the respective challenge virus at 14 days post-secondary inoculation (Table 3). Figure 2B illustrates the more rapid development of $\mathrm{VN}$ antibodies against the challenge virus in challenge control pigs than in pH1N1-immune pigs. Anti$\mathrm{pH} 1 \mathrm{~N} 1$ antibody titers remained at pre-challenge levels in group A, B and C in all assays ( $p>0.05)$, but increased significantly in group $\mathrm{D}$ in $\mathrm{HI}$ and $\mathrm{VN}$ assays $(p<0.05)$ (Additional file 3).

Table 3 Geometric mean antibody titers in hemagglutination-inhibition (HI), virus-neutralization (VN), and neuraminidaseinhibition (NI) assays at 14 days post-inoculation of pigs with various influenza viruses.

\begin{tabular}{|c|c|c|c|c|c|c|c|c|c|c|c|c|c|c|c|c|}
\hline \multirow{3}{*}{ Virus for inoculation } & \multirow{3}{*}{ No. of pigs } & \multicolumn{15}{|c|}{ Antibody titer against } \\
\hline & & \multicolumn{3}{|c|}{ A/California/04/09 } & \multicolumn{3}{|c|}{ Sw/Gent/28/10 } & \multicolumn{3}{|c|}{ Sw/Côtes d'Armor/0046/08 } & \multicolumn{3}{|c|}{ Sw/Gent/26/12 } & \multicolumn{3}{|c|}{ Sw/Gent/172/08 } \\
\hline & & $\overline{\mathrm{HI}}$ & $\mathrm{VN}$ & $\mathrm{NI}$ & $\overline{\mathrm{HI}}$ & VN & $\mathrm{Nl}$ & $\overline{\mathrm{HI}}$ & VN & $\mathrm{Nl}$ & $\overline{\mathrm{HI}}$ & VN & $\mathrm{NI}$ & $\overline{\mathrm{HI}}$ & VN & $\mathrm{NI}$ \\
\hline A/California/04/09 (pH1N1) & 20 & 89 & 76 & 109 & $<10$ & 3 & 16 & $<10$ & 9 & 22 & $<10$ & 4 & $<10$ & $<10$ & $<2$ & $<10$ \\
\hline Sw/Gent/28/10 (H1N1) & 5 & $<10$ & 3 & 16 & 80 & 384 & 320 & $<10$ & 3 & 40 & $<10$ & 4 & $<10$ & $<10$ & $<2$ & $<10$ \\
\hline $\begin{array}{l}\text { Sw/Côtes d'Armor/0046/08 } \\
\text { (rH1N1) }\end{array}$ & 5 & $<10$ & 2 & 30 & $<10$ & $<2$ & 40 & 70 & 795 & 211 & 20 & 262 & $<10$ & $<10$ & $<2$ & $<10$ \\
\hline Sw/Gent/26/12 (H1N2) & 5 & $<10$ & $<2$ & $<10$ & $<10$ & $<2$ & $<10$ & 15 & 114 & $<10$ & 127 & 1276 & 46 & $<10$ & $<2$ & 15 \\
\hline Sw/Gent/172/08 (H3N2) & 3 & $<10$ & $<2$ & $<10$ & $<10$ & $<2$ & $<10$ & $<10$ & $<2$ & $<10$ & $<10$ & $<2$ & 12 & 160 & 347 & 381 \\
\hline
\end{tabular}

The detection limits were 1:2 in the VN assay, and 1:10 in $\mathrm{HI}$ and $\mathrm{NI}$ assays. Negative samples were assigned a value of half the minimum detectable titer for the calculation of geometric mean antibody titers. Values in bold are titers against the homologous virus. 
A

pH1N1 challenge (group A)
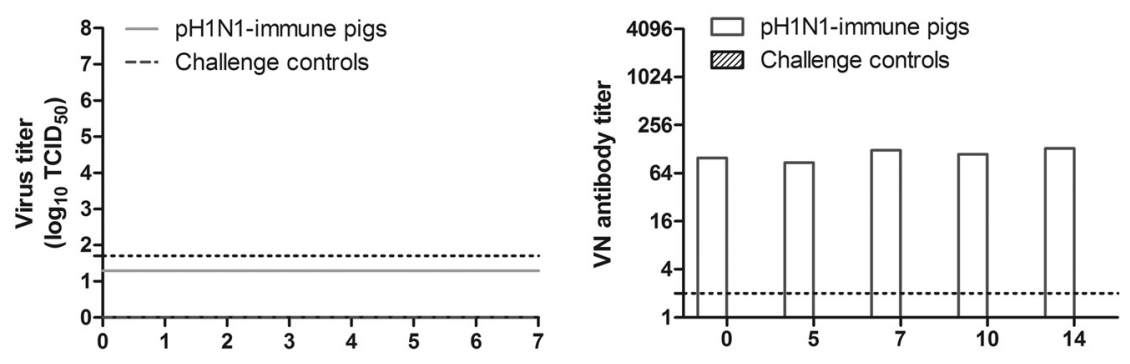

H1N1 challenge (group B, E)
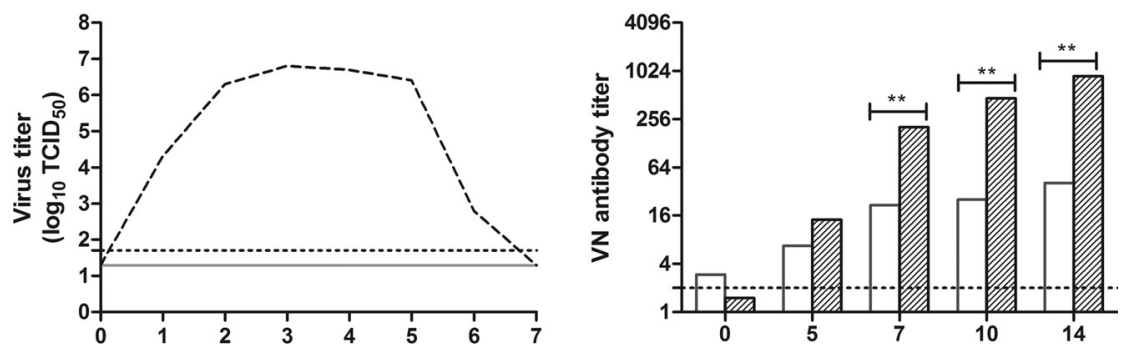

rH1N1 challenge (group C, F)
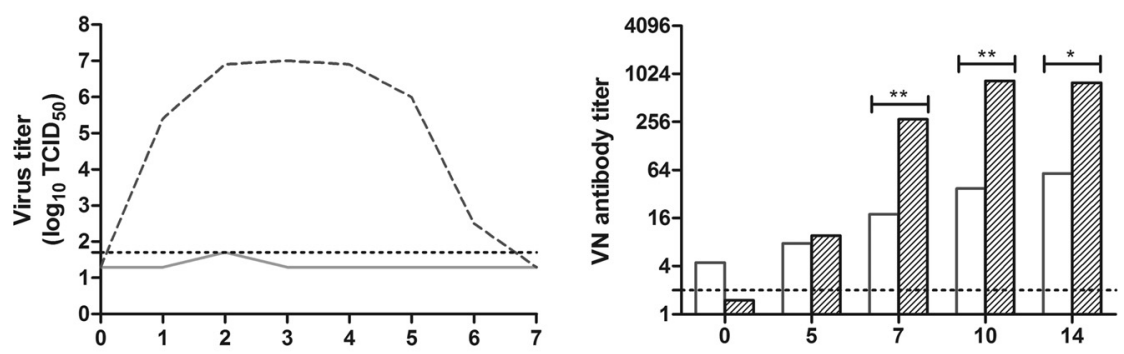

H1N2 challenge (group D, G)
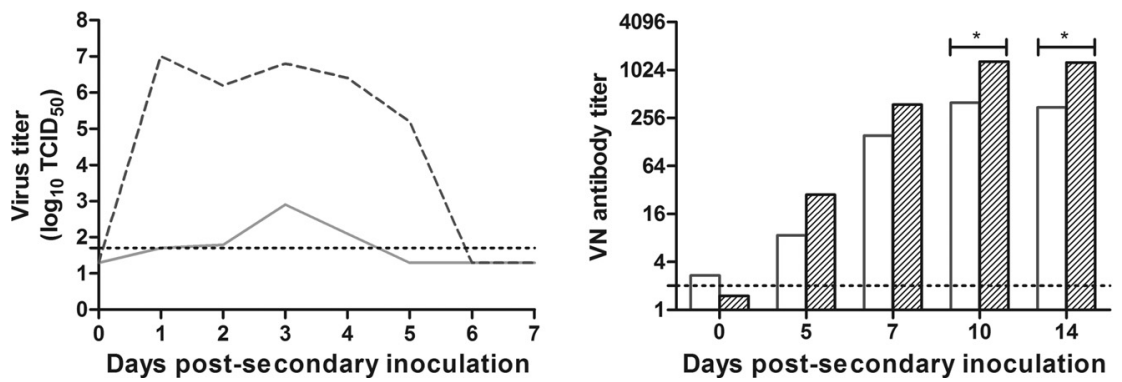

Figure 2 Virus titers in nasal swabs (A) and virus-neutralizing (VN) antibody titers in serum (B) post-secondary inoculation with various H1 viruses. Nasal swabs were collected daily from day 0 to 7 post-secondary inoculation to determine virus titers per 100 mg nasal secretions. VN antibody titers were determined against the respective challenge $\mathrm{H} 1$ virus on days $0,5,7,10$ and 14 post-secondary inoculation. Horizontal dotted lines represent the detection limit of the assay: $1.7 \log _{10} \mathrm{TCID}_{50}$ for virus titration, 2 for the $\mathrm{VN}$ assay. ${ }^{*} p<0.05$ and ${ }^{* *} p<0.01$, by the Mann-Whitney test. 


\section{Experiment 2: protection against challenge with a European H3N2 SIV in pigs with infection immunity against various $\mathrm{H} 1$ virus(es)}

Figure 3A shows mean virus titers in nasal swabs posttertiary inoculation with a European H3N2 SIV. All challenge control pigs (group $\mathrm{H}$ ), pigs immune to $\mathrm{pH} 1 \mathrm{~N} 1$ (group A) or pH1N1 followed by H1N1 (group B) shed high titers of virus for 4-6 days (mean $\mathrm{AUC}=23.2$, 18.9 or 16.4, respectively). All H1N1-immune pigs (group E) also shed viruses for at least 2-6 days, but the virus titers were reduced (mean AUC =12.3). Only one pig with infection immunity against H1N2 (group G) and two pigs with infection immunity against both $\mathrm{pH} 1 \mathrm{~N} 1$ and $\mathrm{H} 1 \mathrm{~N} 2$ (group D) had detectable virus excretion (mean AUC = 0.14 and 1.65 , respectively). Figure $3 \mathrm{~B}$ shows individual virus titers in the respiratory tract of 2 pigs of each group at 4 days post-tertiary inoculation. Challenge control pigs (group $\mathrm{H}$ ) were virus-positive in all tissues, except for the olfactory region of the nasal mucosa of one pig. Virus isolation rates and virus titers in the other groups reflected those in nasal swabs. Pigs immune to pH1N1 (group A) or both pH1N1 and H1N1 (group B) showed only a minimal reduction of virus replication. A higher reduction of virus titers was observed in the pigs immune to H1N1 alone (group E), while those immune to $\mathrm{H} 1 \mathrm{~N} 2$ alone (group G) or pH1N1 followed by H1N2 (group D) were almost completely protected against $\mathrm{H} 3 \mathrm{~N} 2$ replication.

All pigs lacked $\mathrm{HI}$ and $\mathrm{VN}$ antibodies against $\mathrm{H} 3 \mathrm{~N} 2$ before the tertiary inoculation. Cross-NI antibodies against H3N2 were only detected in pigs previously exposed to $\mathrm{H} 1 \mathrm{~N} 2$, and titers were higher in group G (GMT 70) than in group $\mathrm{D}(\mathrm{GMT} 17)(p<0.05)$. At 14 days post-tertiary inoculation with $\mathrm{H} 3 \mathrm{~N} 2$, all pigs developed antibodies or showed an increase in pre-existing antibody titers against H3N2 (Table 4). Antibody titers against $\mathrm{H} 1$ viruses remained at pre-challenge level in all assays $(p>0.05)$.

\section{Discussion}

We have shown nearly complete cross-protection against replication of European H1 SIV lineages in pigs with infection immunity against pH1N1, but only a weak crossprotection against the H3N2 subtype in pigs with infection immunity against various H1N1 viruses. In line with previous studies [9,27], all three H1 SIVs used in our studies failed to cross-react with $\mathrm{pH} 1 \mathrm{~N} 1$ in $\mathrm{HI}$ assays with postinfection swine sera, and there was minimal cross-reactivity in $\mathrm{VN}$ assays. The $\mathrm{VN}$ assay is known to be more sensitive than the HI assay, and the former assay does not only detect antibodies that inhibit the attachment of the virus to target cells, but also antibodies that can block the fusion of the viral and endosomal membranes [28]. Cross-HI assays with high-titered hyperimmune swine sera have also shown low levels of cross-reactivity between pH1N1 and European avian-like H1N1 but not human-like H1N2 SIVs [27]. The
HA1 of the European H1 SIVs had similar low percentages (69-71\%) of amino acid homology to pH1N1. However, a detailed analysis of the antigenic sites revealed fewer amino acid differences between the classical $\mathrm{H} 1$ of $\mathrm{pH} 1 \mathrm{~N} 1$ and the avian-like $\mathrm{H} 1$ of $\mathrm{H} 1 \mathrm{~N} 1$ as compared to the human-like $\mathrm{H} 1$ of rH1N1 and H1N2 SIVs. Interestingly, the Sa (13 amino acids) site is an immunodominant antigenic site [29-31], and was found to be completely conserved between the first two viruses as previously reported [32], while there were 5-6 amino acid differences between pH1N1 and the human-like H1 SIVs. This may explain why the pH1N1immune pigs in our study were best protected against the avian-like H1N1 SIV. A complete cross-protection against the $\mathrm{pH} 1 \mathrm{~N} 1$ after prior infection of pigs with the avian-like H1N1 SIV has been demonstrated in a previous study [9]. Likewise, prior infection or vaccination with a 1918 pandemic or classical swine H1N1 virus, which differ from pH1N1 in only 1 amino acid in the Sa antigenic site, resulted in nearly complete protection from the latter virus in mice and ferrets [33-35]. Furthermore, there is strong evidence for cross-protection between pH1N1 and historical human seasonal H1N1 viruses from the 1930$40 \mathrm{~s}$ in humans and in experimental animal models $[34,36,37]$. Yet, these viruses have only $67-76 \%$ amino acid homologies in their HA1 and as many as 5 amino acid differences in the Sa antigenic site [34]. Some of the viruses used for prior infection and challenge in the present study also have NAs of the same lineage. This was the case for pH1N1 and European SIVs of the H1N1 subtype (H1N1 and rH1N1), as well as for the European H1N2 and H3N2 SIVs. Unlike antibodies against HA, antiNA antibodies cannot neutralize influenza viruses, but they do play a significant secondary role in protection against influenza in humans and animals [38-41]. Therefore, it is not surprising that $\mathrm{pH} 1 \mathrm{~N} 1$-immune pigs were better protected against European H1N1 than H1N2 SIVs, and that H1N2-immune pigs were better protected against H3N2 challenge than H1N1-immune pigs.

Protection between viruses of H1N1 and H3N2 subtype was clearly less robust than that between viruses of the same HA and/or NA subtype. Yet, pigs with infection immunity against the avian-like H1N1 SIV were better protected against $\mathrm{H} 3 \mathrm{~N} 2$ than $\mathrm{pH} 1 \mathrm{~N} 1$-immune pigs. This suggests a contribution of immune responses against internal proteins, which are shared between avian-like H1N1 and human-like H3N2 SIVs but are of different origins in pH1N1, except for the $M$ protein. In pigs that had been subsequently exposed to pH1N1 and the avian-like H1N1, protection against $\mathrm{H} 3 \mathrm{~N} 2$ was similar to that in pigs exposed twice to $\mathrm{pH} 1 \mathrm{~N} 1$, and inferior to that in pigs exposed to $\mathrm{H} 1 \mathrm{~N} 1$ alone. This is most likely due to the failure of the $\mathrm{H} 1 \mathrm{~N} 1$ virus to replicate and induce specific immune responses in $\mathrm{pH} 1 \mathrm{~N} 1$-immune pigs, as indicated by the nasal virus titers and serological responses. Our data are largely 

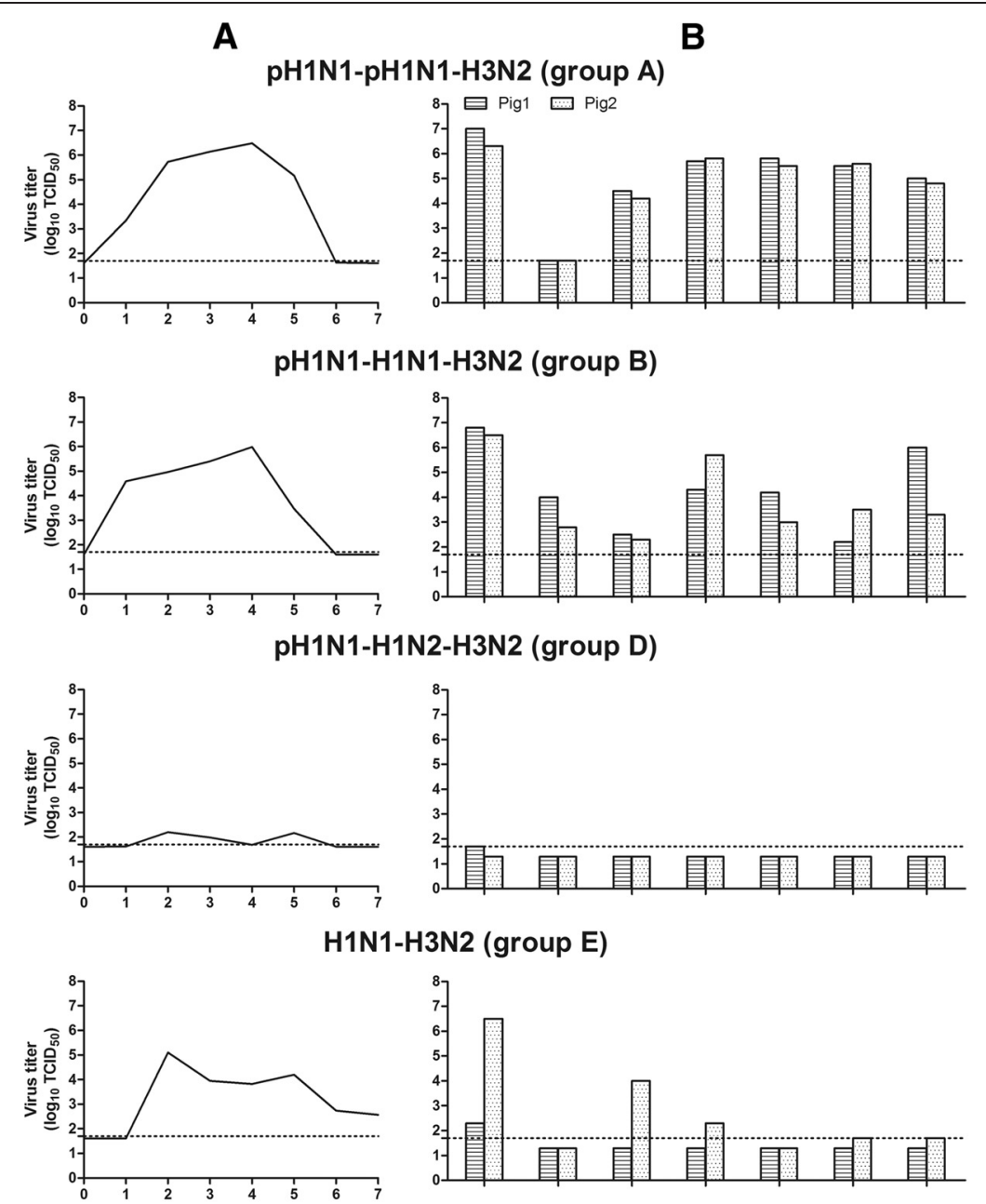

H1N2-H3N2 (group G)
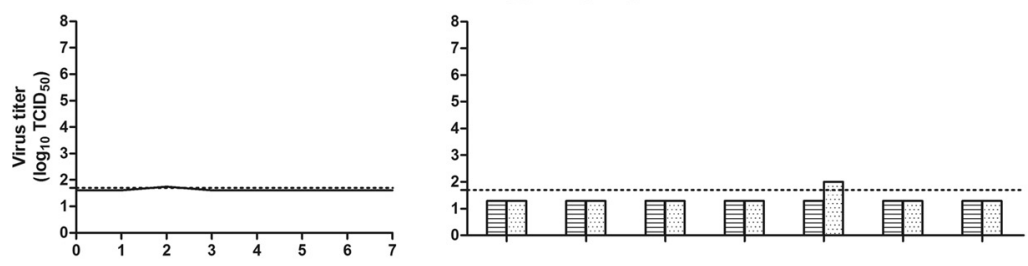

H3N2 control (group H)
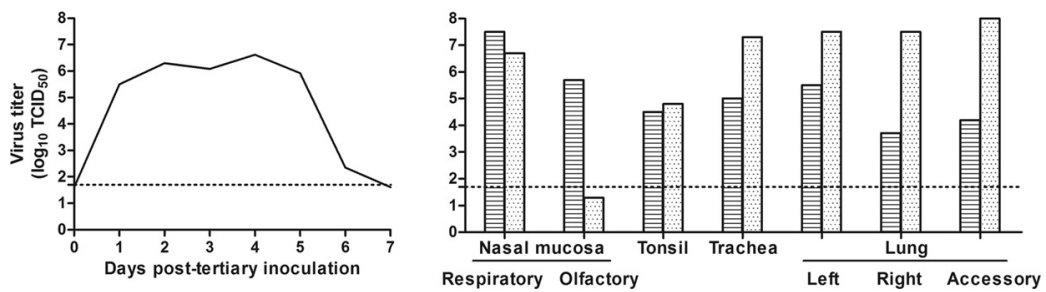

Figure 3 Virus titers in nasal swabs (A) and respiratory tissues (B) post-tertiary inoculation with H3N2. Nasal swabs were collected daily from day 0 to 7 post-tertiary inoculation to determine virus titers per $100 \mathrm{mg}$ nasal secretions. Two pigs per group were euthanized at day 4 post-tertiary inoculation to determine virus titers in $1 \mathrm{~g}$ respiratory tissues. Horizontal dotted lines represent the detection limit for virus titration: 1.7 $\log _{10} \mathrm{TCID}_{50}$. 
Table 4 Geometric mean antibody titers against the H3N2 virus in hemagglutination-inhibition (HI), virus-neutralization (VN), and neuraminidase-inhibition (NI) assays at 14 days post-tertiary inoculation with $\mathrm{H} 3 \mathrm{~N} 2$

\begin{tabular}{lllll}
\hline Group & Virus inoculations & HI & VN & NI \\
\hline A & pH1N1-6w-pH1N1-17w-H3N2 & 202 & 116 & 320 \\
B & pH1N1-6w-H1N1-17w-H3N2 & 254 & 266 & 254 \\
D & pH1N1-6w-H1N2-17w-H3N2 & 16 & 26 & 320 \\
E & Mock-6w-H1N1-17w-H3N2 & 127 & 185 & 320 \\
G & Mock-6w-H1N2-17w-H3N2 & 20 & 16 & 320 \\
H & Mock-6w-mock-17w-H3N2 & 160 & 347 & 381 \\
\hline
\end{tabular}

in agreement with previous studies on heterosubtypic protection in pigs, ferrets, and mice [11,13-16,42], none of which showed a complete protection between $\mathrm{H} 1$ and $\mathrm{H} 3$ viruses. For example, prior infection of ferrets with $\mathrm{pH} 1 \mathrm{~N} 1$ or a seasonal H1N1 virus resulted in a shorter duration of nasal excretion of seasonal H3N2 virus, i.e. 5 days instead of 7 days in unprimed influenza naïve ferrets $[13,15]$. In mice, prior infection with $\mathrm{H} 1 \mathrm{~N} 1$ or $\mathrm{pH} 1 \mathrm{~N} 1$ did not reduce $\mathrm{H} 3 \mathrm{~N} 2$ virus titers in the lungs at 4 days post-challenge, but titers were undetectable or reduced by $10^{4}$-fold at 7 days post-challenge [11,42].

Although heterosubtypic protection has been frequently studied in mice, the pig model has some specific advantages for studying protection between influenza viruses. Pigs are natural hosts for a variety of genetically and antigenically diverse $\mathrm{H} 1$ and $\mathrm{H} 3$ viruses. Most SIVs have an HA derived from viruses that once circulated in humans and the pH1N1 is a shared virus between humans and swine [43]. Nearly all SIVs are natural reassortants. As a result, the SIVs used in this study share one to seven genes with each other, and this allows examination of the relative importance of the corresponding proteins for protection. As pointed out before [44-46], the pathogenesis of influenza is very similar in pigs and in humans, and there are also striking similarities in their immune responses. In mice, the outcome of infection experiments depends on the mouse and virus strain used. For instance, upon infection with PR/8, DBA/2 mice showed a greater susceptibility to infection, more rapid weight loss and death, elevated cytokine production, and more severe lung histopathology than C57BL/6 mice [47]. Also, human influenza viruses generally require adaptation to be able to replicate and achieve virulence in mice, and the adapted virus may be antigenically and phenotypically very different from the initial strain [48]. Finally, mice transmit influenza viruses inefficiently and nasal virus excretion cannot be evaluated in mice [49]. Pigs, in contrast, are highly susceptible to a variety of human $\mathrm{H} 1$ and $\mathrm{H} 3$ viruses [24,50,51]. And unlike mice, pigs can shed high titers of virus in nasal swabs for 4-6 days.
During the last few years, there have been several serologic investigations for cross-reactive antibodies against European $\mathrm{H} 1$ and H3 SIVs in humans of different age categories [52-54]. HI antibodies against the European H3N2 SIV were present in 70\% of those born before 1990, but were rare in the younger population [54]. In comparison, HI antibodies against the European avianlike H1N1 SIV were detected in only approximately $10 \%$ of humans in 2009, and they showed only a minimal increase in humans with seroconversion to $\mathrm{pH} 1 \mathrm{~N} 1$ $[53,55,56]$. This is in agreement with our finding that pH1N1 infection did not induce detectable serum HI antibodies against the avian-like H1N1 SIV. On the other hand, pH1N1-immune pigs showed a complete virological protection against the avian-like H1N1 SIV. This further supports the notion that infection with a live influenza virus can induce cross-protection in the absence of cross-reactive serum HI antibodies and argues for more in vivo cross-protection studies in animal models. From such studies, we conclude that humans, especially the young population born after 1990, will likely have better immune protection against European H1 than H3 SIVs. This is based on the presence of minimal protection against European H3N2 SIVs in pigs with infection immunity against contemporary human H3N2 viruses [24] or pH1N1, whereas infection immunity against $\mathrm{pH} 1 \mathrm{~N} 1$ seems to offer significant protection against the major H1 SIVs.

In conclusion, our study shows that infection with a live, wild type influenza virus may offer substantial crosslineage protection against viruses of the same $\mathrm{HA}$ and/or NA subtype. Heterosubtypic protection between viruses of different HA and NA subtypes, in contrast, appears to be weak in pigs. Because they are natural hosts for the same influenza virus subtypes as humans, pigs have some unique advantages as a model for cross-protection studies with influenza. According to our data, the global spread of pH1N1 in humans will enhance their cross-protective immunity against European H1 SIVs, making those viruses less likely to cause pandemics in the near future.

\section{Additional files}

Additional file 1: Alignment of deduced amino acid sequences in
the HA1 of A/California/04/09 ( $\mathrm{pH} 1 \mathrm{~N} 1)$, sw/Gent/28/10 (H1N1), sw/
Côtes d'Armor/0046/08 (reassortant H1N1), and sw/Gent/26/12
(H1N2). Residues in the open boxes represent previously identified
antigenic sites of H1. Amino acids differing from those in the A/
California/04/09 sequence are shown, conserved residues are represented
as dots.
Additional file 2: Alignment of deduced amino acid sequences in
the NA of sw/Gent/172/08 (H3N2) and sw/Gent/26/12 (H1N2).
Residues in the open boxes represent previously identified antigenic sites
of N2. Amino acids differing from those in the sw/Gent/172/08 sequence
are shown, conserved residues are represented as dots.


Additional file 3: Serological profile after inoculation with various $\mathrm{H} 1$ viruses in $\mathrm{pH} 1 \mathrm{~N} 1$-immune pigs. Antibody titers were determined at 14 days post-secondary inoculation in hemagglutination-inhibition $(\mathrm{HI})$, virusneutralization (VN), and neuraminidase-inhibition (NI) assays.

\section{Competing interests}

The authors declare that they have no competing interests.

\section{Authors' contributions}

YQ participated in the design of the study, performed the experiments, analyzed the data and wrote the manuscript. $\mathrm{KDH}$ helped with the experiments and sample collection. KVR designed and coordinated the study and wrote the manuscript. All authors read and approved the final manuscript.

\section{Acknowledgements}

The authors thank Dr Gaëlle Kuntz-Simon for providing the sw/Côtes d'Armor/ 0046/08 virus, as well as Lieve Sys, Melanie Bauwens, Nele Dennequin, Zeger van den Abeele and Philippe Elskens for excellent technical assistance, and Ivy Brown for proof reading the manuscript. This study was funded by the Belgian Federal Service for Public Health, Food Chain Safety and Environment (FLUCROSS, RT 09/ 6227) and the European Commission (FLUPIG, FP7-GA 258084).

Received: 4 March 2015 Accepted: 6 August 2015

Published online: 24 September 2015

\section{References}

1. Pensaert M, Ottis K, Vandeputte J, Kaplan MM, Bachmann PA (1981) Evidence for the natural transmission of influenza A virus from wild ducks to swine and its potential importance for man. Bull World Health Organ 59:75-78

2. Castrucci MR, Donatelli I, Sidoli L, Barigazzi G, Kawaoka Y, Webster RG (1993) Genetic reassortment between avian and human influenza A viruses in Italian pigs. Virology 193:503-506

3. Campitelli L, Donatelli I, Foni E, Castrucci MR, Fabiani C, Kawaoka Y, Krauss S, Webster RG (1997) Continued evolution of H1N1 and H3N2 influenza viruses in pigs in Italy. Virology 232:310-318

4. Van Reeth K, Brown $1 \mathrm{H}$, Pensaert M (2000) Isolations of H1N2 influenza A virus from pigs in Belgium. Vet Rec 146:588-589

5. Brown IH, Harris PA, McCauley JW, Alexander DJ (1998) Multiple genetic reassortment of avian and human influenza A viruses in European pigs, resulting in the emergence of an H1N2 virus of novel genotype. J Gen Virol 79:2947-2955

6. Garten RJ, Davis CT, Russell CA, Shu B, Lindstrom S, Balish A, Sessions WM, Xu X, Skepner E, Deyde V, Okomo-Adhiambo M, Gubareva L, Barnes J, Smith CB, Emery SL, Hillman MJ, Rivailler P, Smagala J, de Graaf M, Burke DF, Fouchier RA, Pappas C, Alpuche-Aranda CM, Lopez-Gatell H, Olivera H, Lopez I, Myers CA, Faix D, Blair PJ, Yu C et al. (2009) Antigenic and genetic characteristics of swine-origin 2009 A(H1N1) influenza viruses circulating in humans. Science 325:197-201

7. Nelson MI, Vincent AL (2015) Reverse zoonosis of influenza to swine: new perspectives on the human-animal interface. Trends Microbiol 23:142-153

8. Simon G, Larsen LE, Durrwald R, Foni E, Harder T, Van Reeth K, MarkowskaDaniel I, Reid SM, Dan A, Maldonado J, Huovilainen A, Billinis C, Davidson I, Aguero M, Vila T, Herve S, Breum SO, Chiapponi C, Urbaniak K, Kyriakis CS, Brown $H$, Loeffen W (2014) European surveillance network for influenza in pigs: surveillance programs, diagnostic tools and swine influenza virus subtypes identified in 14 European countries from 2010 to 2013. PLoS One 9:e115815

9. Busquets N, Segales J, Cordoba L, Mussa T, Crisci E, Martin-Valls GE, SimonGrife M, Perez-Simo M, Perez-Maillo M, Nunez Jl, Abad FX, Fraile L, Pina S, Majo N, Bensaid A, Domingo M, Montoya M (2010) Experimental infection with $\mathrm{H} 1 \mathrm{~N} 1$ European swine influenza virus protects pigs from an infection with the 2009 pandemic H1N1 human influenza virus. Vet Res 41:74

10. De Vleeschauwer AR, Van Poucke SG, Karasin Al, Olsen CW, Van Reeth K (2011) Cross-protection between antigenically distinct H1N1 swine influenza viruses from Europe and North America. Influenza Other Respi Viruses 5:115-122

11. Kreijtz JH, Bodewes R, van Amerongen G, Kuiken T, Fouchier RA, Osterhaus $A D$, Rimmelzwaan GF (2007) Primary influenza A virus infection induces cross-protective immunity against a lethal infection with a heterosubtypic virus strain in mice. Vaccine 25:612-620
12. Straight TM, Ottolini MG, Prince GA, Eichelberger MC (2006) Evidence of a cross-protective immune response to influenza $A$ in the cotton rat model. Vaccine 24:6264-6271

13. Yetter RA, Barber WH, Small PA Jr (1980) Heterotypic immunity to influenza in ferrets. Infect Immun 29:650-653

14. Liang S, Mozdzanowska K, Palladino G, Gerhard W (1994) Heterosubtypic immunity to influenza type A virus in mice: effector mechanisms and their longevity. J Immunol 152:1653-1661

15. Laurie KL, Carolan LA, Middleton D, Lowther S, Kelso A, Barr IG (2010) Multiple infections with seasonal influenza A virus induce cross-protective immunity against $A(\mathrm{H} 1 \mathrm{~N} 1)$ pandemic influenza virus in a ferret model. J Infect Dis 202:1011-1020

16. Heinen PP, de Boer-Luijtze EA, Bianchi AT (2001) Respiratory and systemic humoral and cellular immune responses of pigs to a heterosubtypic influenza A virus infection. J Gen Virol 82:2697-2707

17. Sonoguchi T, Naito H, Hara M, Takeuchi Y, Fukumi H (1985) Cross-subtype protection in humans during sequential, overlapping, and/or concurrent epidemics caused by H3N2 and H1N1 influenza viruses. J Infect Dis 151:81-88

18. Lavenu A, Valleron AJ, Carrat F (2004) Exploring cross-protection between influenza strains by an epidemiological model. Virus Res 103:101-105

19. Epstein SL (2006) Prior H1N1 influenza infection and susceptibility of Cleveland Family Study participants during the H2N2 pandemic of 1957: an experiment of nature. J Infect Dis 193:49-53

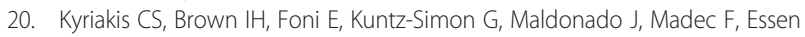
SC, Chiapponi C, Van Reeth K (2011) Virological surveillance and preliminary antigenic characterization of influenza viruses in pigs in five European countries from 2006 to 2008. Zoonoses Public Health 58:93-101

21. Brownlee $\mathrm{GG}$, Fodor $\mathrm{E}$ (2001) The predicted antigenicity of the haemagglutinin of the 1918 Spanish influenza pandemic suggests an avian origin. Philos Trans R Soc Lond B Biol Sci 356:1871-1876

22. Colman PM, Varghese JN, Laver WG (1983) Structure of the catalytic and antigenic sites in influenza virus neuraminidase. Nature 303:41-44

23. Tamura K, Peterson D, Peterson N, Stecher G, Nei M, Kumar S (2011) MEGA5: molecular evolutionary genetics analysis using maximum likelihood, evolutionary distance, and maximum parsimony methods. Mol Biol Evol 28:2731-2739

24. Qiu Y, van der Meulen K, Van Reeth K (2013) Prior infection of pigs with a recent human $\mathrm{H} 3 \mathrm{~N} 2$ influenza virus confers minimal cross-protection against a European swine H3N2 virus. Influenza Other Respir Viruses 7:1260-1268

25. Van Reeth K, Gregory V, Hay A, Pensaert M (2003) Protection against a European H1N2 swine influenza virus in pigs previously infected with H1N1 and/or H3N2 subtypes. Vaccine 21:1375-1381

26. Sandbulte MR, Gao J, Straight TM, Eichelberger MC (2009) A miniaturized assay for influenza neuraminidase-inhibiting antibodies utilizing reverse genetics-derived antigens. Influenza Other Respi Viruses 3:233-240

27. Kyriakis CS, Olsen CW, Carman S, Brown IH, Brookes SM, Doorsselaere JV, Van Reeth K (2010) Serologic cross-reactivity with pandemic (H1N1) 2009 virus in pigs, Europe. Emerg Infect Dis 16:96-99

28. Brandenburg B, Koudstaal W, Goudsmit J, Klaren V, Tang C, Bujny MV, Korse HJ, Kwaks T, Otterstrom JJ, Juraszek J, van Oijen AM, Vogels R, Friesen RH (2013) Mechanisms of hemagglutinin targeted influenza virus neutralization. PLoS One 8:e80034

29. O'Donnell CD, Vogel L, Wright A, Das SR, Wrammert J, Li GM, McCausland M, Zheng NY, Yewdell JW, Ahmed R, Wilson PC, Subbarao K (2012) Antibody pressure by a human monoclonal antibody targeting the 2009 pandemic H1N1 virus hemagglutinin drives the emergence of a virus with increased virulence in mice. MBio 3:e00120-12

30. Strengell M, Ikonen N, Ziegler T, Julkunen I (2011) Minor changes in the hemagglutinin of influenza A(H1N1)2009 virus alter its antigenic properties. PLoS One 6:e25848

31. Retamal M, Abed Y, Corbeil J, Boivin G (2014) Epitope mapping of the 2009 pandemic and the A/Brisbane/59/2007 seasonal (H1N1) influenza virus haemagglutinins using mAbs and escape mutants. J Gen Virol 95:2377-2389

32. Castrucci MR, Facchini M, Di Mario G, Garulli B, Sciaraffia E, Meola M, Fabiani C, De Marco MA, Cordioli P, Siccardi A, Kawaoka Y, Donatelli I (2014) Modified vaccinia virus Ankara expressing the hemagglutinin of pandemic (H1N1) 2009 virus induces cross-protective immunity against Eurasian 'avian-like' H1N1 swine viruses in mice. Influenza Other Respir Viruses 8:367-375

33. Kash JC, Qi L, Dugan VG, Jagger BW, Hrabal RJ, Memoli MJ, Morens DM, Taubenberger JK (2010) Prior infection with classical swine H1N1 influenza viruses is associated with protective immunity to the 2009 pandemic H1N1 virus. Influenza Other Respi Viruses 4:121-127 
34. O'Donnell CD, Wright A, Vogel LN, Wei CJ, Nabel GJ, Subbarao K (2012) Effect of priming with $\mathrm{H} 1 \mathrm{~N} 1$ influenza viruses of variable antigenic distances on challenge with 2009 pandemic H1N1 virus. J Virol 86:8625-8633

35. Manicassamy B, Medina RA, Hai R, Tsibane T, Stertz S, Nistal-Villan E, Palese P, Basler CF, Garcia-Sastre A (2010) Protection of mice against lethal challenge with 2009 H1N1 influenza A virus by 1918-like and classical swine H1N1 based vaccines. PLoS Pathog 6:e1000745

36. Skowronski DM, Hottes TS, McElhaney JE, Janjua NZ, Sabaiduc S, Chan T, Gentleman B, Purych D, Gardy J, Patrick DM, Brunham RC, De Serres G, Petric M (2011) Immuno-epidemiologic correlates of pandemic H1N1 surveillance observations: higher antibody and lower cell-mediated immune responses with advanced age. J Infect Dis 203:158-167

37. Skountzou I, Koutsonanos DG, Kim JH, Powers R, Satyabhama L, Masseoud F, Weldon WC, Martin Mdel P, Mittler RS, Compans R, Jacob J (2010) Immunity to pre-1950 H1N1 influenza viruses confers cross-protection against the pandemic swine-origin 2009 A (H1N1) influenza virus. J Immunol 185:1642-1649

38. Monto AS, Kendal AP (1973) Effect of neuraminidase antibody on Hong Kong influenza. Lancet 1:623-625

39. Schulman JL, Khakpour M, Kilbourne ED (1968) Protective effects of specific immunity to viral neuraminidase on influenza virus infection of mice. J Virol 2:778-786

40. Sylte MJ, Hubby B, Suarez DL (2007) Influenza neuraminidase antibodies provide partial protection for chickens against high pathogenic avian influenza infection. Vaccine 25:3763-3772

41. Kilbourne ED, Pokorny BA, Johansson B, Brett I, Milev Y, Matthews JT (2004) Protection of mice with recombinant influenza virus neuraminidase. J Infect Dis 189:459-461

42. Hillaire ML, van Trierum SE, Kreijtz JH, Bodewes R, Geelhoed-Mieras MM, Nieuwkoop NJ, Fouchier RA, Kuiken T, Osterhaus AD, Rimmelzwaan GF (2011) Cross-protective immunity against influenza pH1N1 2009 viruses induced by seasonal influenza A (H3N2) virus is mediated by virus-specific T-cells. J Gen Virol 92:2339-2349

43. Van Reeth K, Brown IH, Olsen CW (2012) Swine influenza. In: Zimmerman JJ, Karriker LA, Ramirez A, Schwartz KJ, Stevenson GW (eds) Diseases of Swine. John Wiley \& Sons, Inc, Hoboken, NJ

44. Van Reeth K, Nauwynck H, Pensaert M (1998) Bronchoalveolar interferon-alpha, tumor necrosis factor-alpha, interleukin-1, and inflammation during acute influenza in pigs: a possible model for humans? J Infect Dis 177:1076-1079

45. Brookes SM, Nunez A, Choudhury B, Matrosovich M, Essen SC, Clifford D, Slomka MJ, Kuntz-Simon G, Garcon F, Nash B, Hanna A, Heegaard PM, Queguiner S, Chiapponi C, Bublot M, Garcia JM, Gardner R, Foni E, Loeffen W, Larsen L, Van Reeth K, Banks J, Irvine RM, Brown IH (2010) Replication, pathogenesis and transmission of pandemic (H1N1) 2009 virus in non-immune pigs. PLoS One 5:e9068

46. Khatri M, Dwivedi V, Krakowka S, Manickam C, Ali A, Wang L, Qin Z, Renukaradhya GJ, Lee CW (2010) Swine influenza H1N1 virus induces acute inflammatory immune responses in pig lungs: a potential animal model for human H1N1 influenza virus. J Virol 84:11210-11218

47. Srivastava B, Blazejewska P, Hessmann M, Bruder D, Geffers R, Mauel S, Gruber AD, Schughart K (2009) Host genetic background strongly influences the response to influenza a virus infections. PLoS One 4:e4857

48. Bouvier NM, Lowen AC (2010) Animal models for influenza virus pathogenesis and transmission. Viruses 2:1530-1563

49. Lowen AC, Mubareka S, Tumpey TM, Garcia-Sastre A, Palese P (2006) The guinea pig as a transmission model for human influenza viruses. Proc Natl Acad Sci U S A 103:9988-9992

50. Landolt GA, Karasin Al, Phillips L, Olsen CW (2003) Comparison of the pathogenesis of two genetically different H3N2 influenza A viruses in pigs. J Clin Microbiol 41:1936-1941

51. Karasin Al, Carman S, Olsen CW (2006) Identification of human H1N2 and human-swine reassortant $\mathrm{H} 1 \mathrm{~N} 2$ and $\mathrm{H} 1 \mathrm{~N} 1$ influenza A viruses among pigs in Ontario, Canada (2003 to 2005). J Clin Microbiol 44:1123-1126

52. Krumbholz A, Lange J, Durrwald R, Walther M, Muller T, Kuhnel D, Wutzler P, Sauerbrei A, Zell R (2014) Prevalence of antibodies to European porcine influenza viruses in humans living in high pig density areas of Germany. Med Microbiol Immun 203:13-24

53. Hoschler K, Thompson C, Casas I, Ellis J, Galiano M, Andrews N, Zambon M (2013) Population susceptibility to North American and Eurasian swine influenza viruses in England, at three time points between 2004 and 2011. Euro Surveill 18:20578
54. Qiu Y, Muller CP, Van Reeth K (2015) Lower seroreactivity to European than to North American H3N2 swine influenza viruses in humans in Luxembourg, 2010. Euro Surveill 20:21078

55. Perera RA, Riley S, Ma SK, Zhu HC, Guan Y, Peiris JS (2011) Seroconversion to pandemic (H1N1) 2009 virus and cross-reactive immunity to other swine influenza viruses. Emerg Infect Dis 17:1897-1899

56. De Marco MA, Porru S, Cordioli P, Cesana BM, Moreno A, Calzoletti L, Bonfanti L, Boni A, Di Carlo AS, Arici C, Carta A, Castrucci MR, Donatelli I, Tomao P, Peri VM, Di Trani L, Vonesch N (2013) Evidence of cross-reactive immunity to 2009 pandemic influenza A virus in workers seropositive to swine H1N1 influenza viruses circulating in Italy. PLoS One 8:e57576

\section{Submit your next manuscript to BioMed Central and take full advantage of:}

- Convenient online submission

- Thorough peer review

- No space constraints or color figure charges

- Immediate publication on acceptance

- Inclusion in PubMed, CAS, Scopus and Google Scholar

- Research which is freely available for redistribution 